\title{
INVESTIGATING BENEFITS AND CRITICISMS OF BIM FOR CONSTRUCTION SCHEDULING IN SMES: AN ITALIAN CASE STUDY
}

\author{
GIADA MALACARNE, GIOVANNI TOLLER, CARMEN MARCHER, \\ MICHAEL RIEDL \& DOMINIK T. MATT \\ Fraunhofer Italia Research, Free University of Bolzano, Italy
}

\begin{abstract}
Scheduling is one of the driving factors in the success of a construction project and it is a critical step for all team members as it provides guidance to where and when they should perform work. Despite its important role, scheduling is typically based on approximate time schedules, which often lead to delays and extra costs. This is due to the lack of visualizing the real effort before the construction phase starts, as well as the difficulty in managing a large number of uncertain factors using traditional approaches. According to many studies, building information modeling aims at improving the quality of construction scheduling by enabling virtual simulations and by promoting digital working space. In this context, following questions arise: How does BIM support the digitalization of the scheduling process? Which are the benefits and criticisms of applying BIM for construction scheduling in a SME environment? This paper aims at evaluating the role of BIM in the digitalization of the construction scheduling process and its suitability for SMEs companies through a real case study. The paper starts with a state of the art on relevant applications of BIM for construction scheduling. Afterwards, the paper suggests a framework for combining construction scheduling and BIM, considering a case study used to verify the feasibility of the integrated method. Finally, findings from the implementation of the proposed framework are summarized, particularly examining the role of $\mathrm{BIM}$ in digitalizing the construction scheduling process, as well as the benefits and criticisms of its applicability to SMEs.
\end{abstract}

Keywords: BIM 4D, Building Information Modeling, Construction Scheduling, SMEs.

\section{INTRODUCTION}

Scheduling plays an essential role in the success of a construction project. Nonetheless, it is traditionally based on unreliable time estimation constructed on past performances and experiences of different professionals. Several studies demonstrate the inefficiency of traditional methods, such as the critical path method (CPM) - used for construction scheduling [1, 2]. In this context, lean construction is one of the innovative trends that promotes efficiency through the optimization of construction processes [3, 4].

Within the framework of the build4future project, Fraunhofer Italia developed the 'Process Reliability in Construction for SMEs' (PRECISE) methodology, which is an innovative methodology to manage the execution phase of a construction project [5]. The PRECISE methodology consists of three phases:

- Early Interdisciplinary Building Design;

- Integral Building Execution Planning (IBEP);

- Dynamic control panel.

In the IBEP phase, companies responsible for executing the work, in collaboration with planners and their key suppliers, develop the process plan for the operations on site. The first step in the development of the process plan is the definition of the following aspects: 
- Construction sections (location);

- The job content for each construction section (by type and amount of work per task);

- Relevant information on each location and task (responsible handcraft, amount of job content, number of workers, main constraints).

The result of this first step is a location-based master schedule. A location-based master schedule represents an overall view that identifies major project phases and milestones in relation with main construction sections [6].

Further comes the definition of pitches, which are the link between the location-based master schedule and the weekly (or daily) scheduling. The concept of 'Pitching' derives from manufacturing sector and establishes a production pace for predictable construction flows [7]. Dallasega et al. [5] define 1 Pitch as the amount of work which can be done by a specific team of craftsmen in a specific construction section in a defined time frame (usually 1 day). This allows easy measurements of the performance of tasks during the execution phase.

Finally, a set of MS-Excel worksheets monitors the execution phase enabling to compare the real progresses on site with the planned ones. For further information on the PRECISE methodology and case studies, please refer to [5] and [8].

Even though the IBEP phase demonstrates that lean construction concepts, such as the Last Planner® System (LPS), when combined with a Location-Based System (LBS), improve the efficiency of construction projects, it shows also two main drawbacks. Firstly, it is relatively low on automation and a high amount of spreadsheets requires manual upload of input data. For instance, when calculating the amount of work for a specific construction section, the user needs to manually extrapolate quantities from CAD files and insert them into the spreadsheets. The same occurs when the user updates the progress from the construction site for performance control. Risk due to human processing is high.

Secondly, the use of spreadsheets is far from being intuitive and the amount of calculations and graphs are hardly understandable by the site supervisor. Therefore, the PRECISE methodology should integrate an object-based parametric methodology to streamline the process.

This paper proposes a BIM framework for construction scheduling to be applied in the context of SMEs. The paper starts with a state of the art on relevant applications of BIM for construction scheduling - with a focus on the Italian and South Tyrolean context - and on the implementation of BIM scheduling in real case studies. Afterwards, the paper presents a framework for combining the PRECISE methodology and BIM, considering a case study used to verify the feasibility of the proposed BIM framework. Finally, findings from the implementation of the proposed framework are summarized and discussed, particularly examining the role of BIM in digitalizing the PRECISE scheduling process, as well as the benefits and criticisms of its applicability to SMEs.

\section{STATE OF THE ART}

2.1 BIM for construction scheduling: an overview of the Italian and South Tyrolean context

BIM in construction scheduling continues to create a higher level of project clarity and it has proven to be an effective means of communication, particularly in complex construction projects [9]. For instance, virtual elements and geometric components are visible in a model environment. By linking these elements to schedule data, a video of the project's construction can be simulated. These simulations enable to communicate visually and analyse project activities and help to reduce delays and sequencing problems. 
Since the interest in 4D BIM applications is steadily growing, several software houses have started to provide dedicated tools. Malsane and Sheth [9] listed a set of BIM tools supporting schedule integration, such as Vico ${ }^{\circledR}$ Software (Trimble), Naviswork's Timeliner ${ }^{\circledR}$ (Autodesk), Innovaya Visual 4D® simulation (Innovaya) and Synchro® Scheduler (Synchro Software).

However, despite of the benefits achievable using BIM for construction scheduling and the technologies already available on the market, Hardin and Mccool [10] argue that the impact of BIM within the 4D phase has not reached the expected impact. A reason for this could be that a large number of contractors are starting realizing with delay the value of the integration of the model with schedule information. Furthermore, effective BIM modelling for 4D purpose requires high IT skills, which are currently either not available or relatively hard to acquire on the market. The lack of adequate IT skills applies in particular to both the Italian and the South Tyrolean (IT) context [11].

In April 2016, the Italian Government published the new regulation on public bids, promoting and requiring the use of electronic tools for modelling and managing of information during a construction project. Since then, the interest on BIM has been constantly growing because of the introduction of this regulation, supposed to become mandatory in the near future [12]. Major Italian construction companies are reacting to tackle this challenge. The management of complex project, such as the Hadid Tower at Milano City Life, already demonstrates the benefits triggered by BIM for the management of execution processes in the Italian context [13].

However, these companies are not representative of the Italian construction sector. In particular, considering the South Tyrolean region, where the construction sector is one of the key industries for the local economy, the $80 \%$ of workers work in SMEs, which provide one third of the total amount of the regional gross domestic product (GDP) [14]. These SMEs risk lagging behind in the globalized market and need support in overcoming challenges such as those emerging from the fourth digital revolution. In fact, BIM is the starting point of the digital revolution in construction and local companies are not prepared to embrace it adequately, as a survey conducted by Fraunhofer Italia in 2015 demonstrates [11].

\subsection{Implementation of BIM scheduling in real case studies}

Since SMEs need a support in facing both challenges related to the optimization of the construction processes and the digital revolution, the research team focused on a literature review on BIM for construction scheduling. The aim was to understand if and how BIM might play a role in overcoming the limitations of the PRECISE methodology.

BIM 4D involves scheduling and sequences of the model to coordinate virtual construction over time and across space [15]. A BIM model collects data and information according to the LOD - Level of Development - of BIM objects. Then, these data are extracted through the Quantity Take-off functionality. As demonstrated by [16], BIM tools support highly accurate quantity take-off and, according to Liu et al. [17], BIM offers the best automate approach to generate accurate quantity take-off from 3D product models, even if detailed construction information is not taken into consideration. In this publication, the authors describe a BIMbased integrated framework for construction scheduling and costs estimation. The integrated framework combines the BIM model with an Integrated WBS (Work Breakdown Structure) and a database containing construction process information. The database stores information and host codes from both the BIM model and the WBS, thus providing for overall automatization. However, this is not sufficient for a complete automated process, since part of the calculation still requires MS-Excel ${ }^{\circledR}$ spreadsheets. Moreover, the overall framework does not fully consider construction sections (locations). 
The Quantity Take-off functionality provides the quantification of each BIM object necessary for calculating task durations. Furthermore, task durations, combined with related BIM objects, allow to simulate construction activities and to evaluate both risks and problems in advance. This makes planning activities and construction management more intuitive. Most of the literature on BIM 4D shows the potentialities of BIM in simulating the execution phase.

Boton et al. [18] tested the use of BIM 4D in a preconstruction and construction case study with a specific focus on simulations. During pre-construction, simulations are effective to sequence the construction activities and to analyse technical constructability. In construction, simulations are effective to control and coordinate the project and to manage logistics. BIM 4D combines Revit ${ }^{\circledR}$ models with MS-Project ${ }^{\circledR}$ schedules uploaded on Navisworks ${ }^{\circledR}$. This is apparently the most common procedure for creating BIM 4D, as demonstrated in other similar studies [9-10]. However, the approach reveals a conceptual problem relating to the LOD definition, which should establish a unique relationship between BIM objects and the WBS associated. The authors used a WBS not at the same LOD as the BIM objects, which led to the definition of an additional WBS specific for BIM objects.

\section{APPROACH DESCRIPTION}

The proposed framework for BIM construction scheduling consists in the integration of three elements namely the Work Breakdown Structure (WBS), the Location Based Structure (LBS) and the Object Parameter Structure (OPS).

The WBS and the LBS entails the lists of the individual project working tasks and the project construction areas respectively. The OPS represents the organization of the parameters into each BIM object. The standard OPS provides information about different parameters of the object according to its LOD - geographic location, shape, measurements, and materials. Additional and customizable parameters can enrich the OPS of each object, according to the purpose of the model.

When planning the construction scheduling using the PRECISE methodology, each object of the model is associated with a specific working task in a specific location. Therefore, the research team introduced two project parameters to the OPS, namely the 'Code WBS' and the 'Code LBS'. These two parameters link the OPS with the WBS and the LBS, establishing a logical and intuitive relationship between activities within locations. Heterogeneous levels of accuracy drive such a relationship. In fact, since each BIM object can integrate only singular WBS and LBS Codes, both the WBS and LBS should be at the same LOD of the BIM object. The proper definition of LBS and WBS according to the LOD of BIM objects leads to an effective and coherent 4D BIM model.

As Figure 1 shows, the research team identifies three main levels of development (LOD). The fourth level represents the pitching level, where objects, work tasks and locations are enough limited to be both measured and controlled on site. Therefore, pitching represents the productivity index for each task in a specific location, visualized through a related BIM pitch. The BIM pitch entails different sizes according to the number of workers and the job contents for specific work tasks within the specific location. Such element enables to daily/weekly control and updates the construction workflow. 


\section{SCHEDULING}

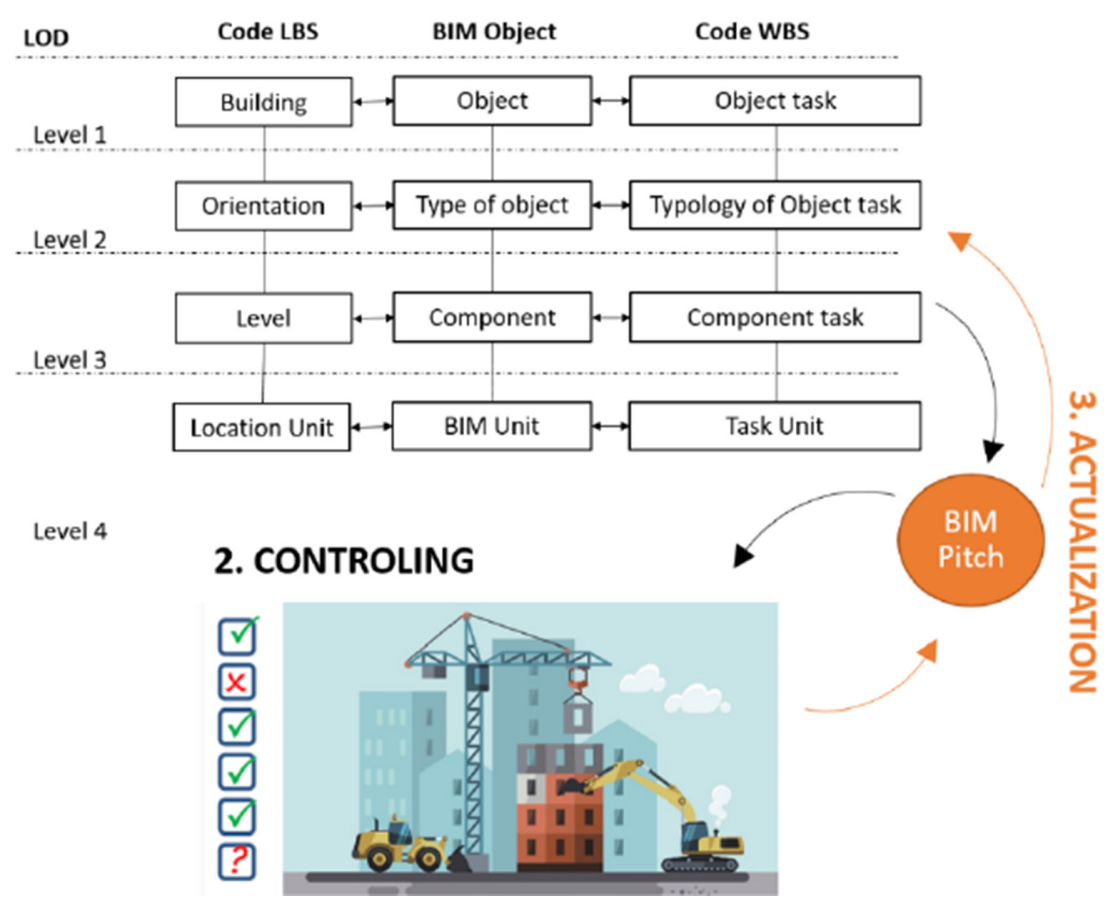

Figure 1: The concept of the proposed BIM framework.

\section{CASE STUDY}

This section illustrates the implementation of the proposed framework for BIM construction scheduling in a real building project. The project is the new main building of the NOI Technology Park located in Bolzano (IT), namely 'The Black Monolith'. This name reflects the main features of the building, characterised by an innovative architectonic shape remembering a giant black stone rooted on earth. The building owns a regular form consisting of two overlapping parallelepipeds. Considering the vertical axis, these are two degrees slopped and covered with a multilayer envelope. The envelope is a unique curtain wall, composed of different layers in order to satisfy highly efficient energy requirements.

Fraunhofer Italia collaborated with a local SME for the optimization of the installation, delivery and production process of the entire envelope system. The optimization process consisted in the application of the PRECISE methodology using traditional tools such as MS Excel spreadsheets, CAD drawings and paper-based information.

During the collaboration, the company expressed the need to visualize the method in a more intuitive way. The request pointed to the development of an easily understandable tool for site supervisors. In this context, besides the employment of traditional tools, the research team tested the suitability of BIM in digitalizing the PRECISE methodology while making it more comprehensible for SMEs. 
The test consisted in the following steps:

1. Development of a mock-up model. The aim of this step was to test the applicability of the proposed BIM framework and of selected technologies;

2. Implementation of the proposed BIM framework to the whole building. The aim of this step was to compare the BIM scheduling process with the traditional one.

The approach adopted is qualitative and results are based on authors' observations.

\subsection{The mock-up model}

The mock-up aimed at testing:

- The applicability of the proposed BIM framework;

- Technologies available on the market and those more suitable with the object of the study;

- The process, the exchange format of the software and the level of automation reachable.

First, the research team decided to model only two façades of the entire building (= Location), representative of two different typologies of the envelope system (= Objects), defining the working tasks of such two typologies (= Job).

These decisions resulted in the organization of the mock-up model of the envelope system and in the definition of the codification system, as shown in Figures 2 and 3.

Afterwards the available technologies on the market have been analysed and selected, leading to the definition of the process shown in Figure 4.

According to the CAD and PDF drawings, the research team developed the BIM model of the envelope system at Level 3 of LOD within the proposed BIM framework. WBS and LBS

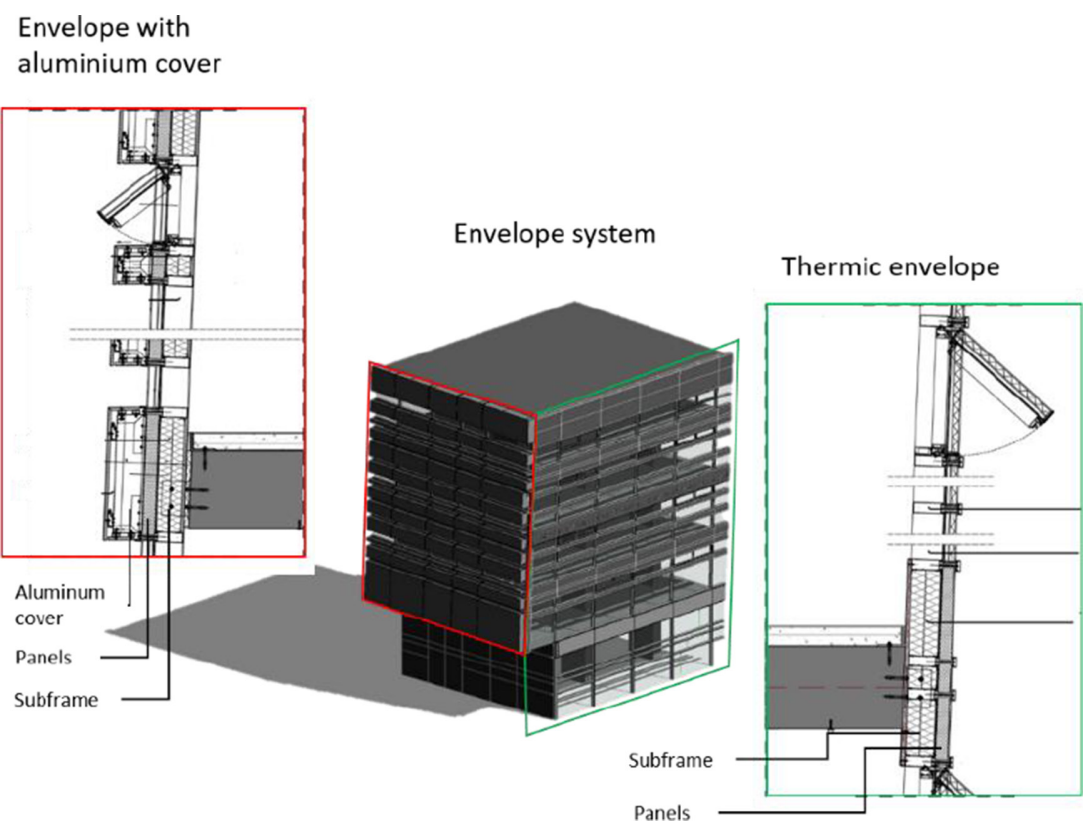

Figure 2: The mock up model of the envelope system. 


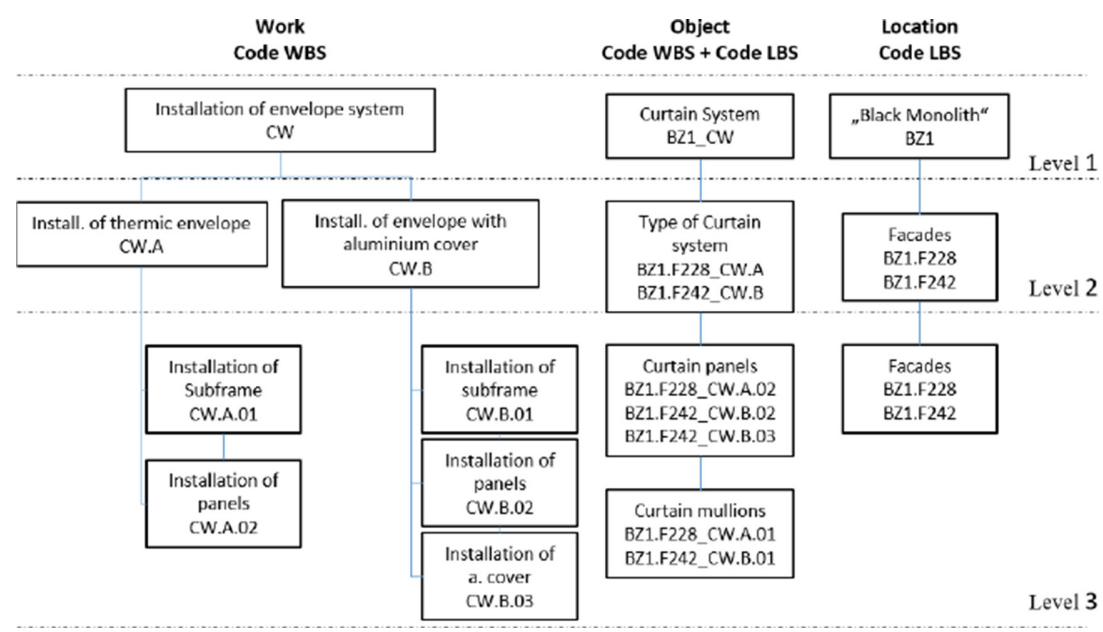

Figure 3: Codification system of the mock-up model.

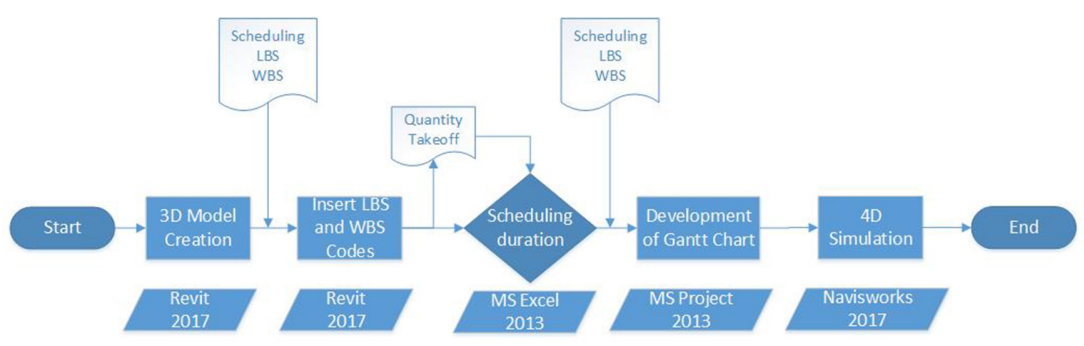

Figure 4: The BIM framework process.

Codes have been manually updated to each curtain panel and curtain mullion according to the curtain system type.

Finally, quantity take-off tables, extracted from the BIM model, provided information about quantities of materials according to Location and working task. Quantity of materials have been consequently imported in MS-Excel® spreadsheets. In this phase, working tasks duration have been calculated through the application of the PRECISE methodology.

The following step has been the development of the Gantt chart. The codification system used to list the working task was the same defined while developing the BIM model. Further, durations have been automatically integrated from the Excel spreadsheet. However, the data exchange were unidirectional, namely from Excel to the Gantt chart only.

Once developed both the BIM model and the Gantt chart, they have been imported in Navisworks ${ }^{\circledR}$ for BIM 4D simulations.

\subsection{The full implementation of the BIM framework}

After the validation of the applicability of the proposed BIM framework, of selected technologies, of exchange formats and of the process, the research team focused on the implementation of the proposed BIM framework to the entire building project (Fig. 5). 


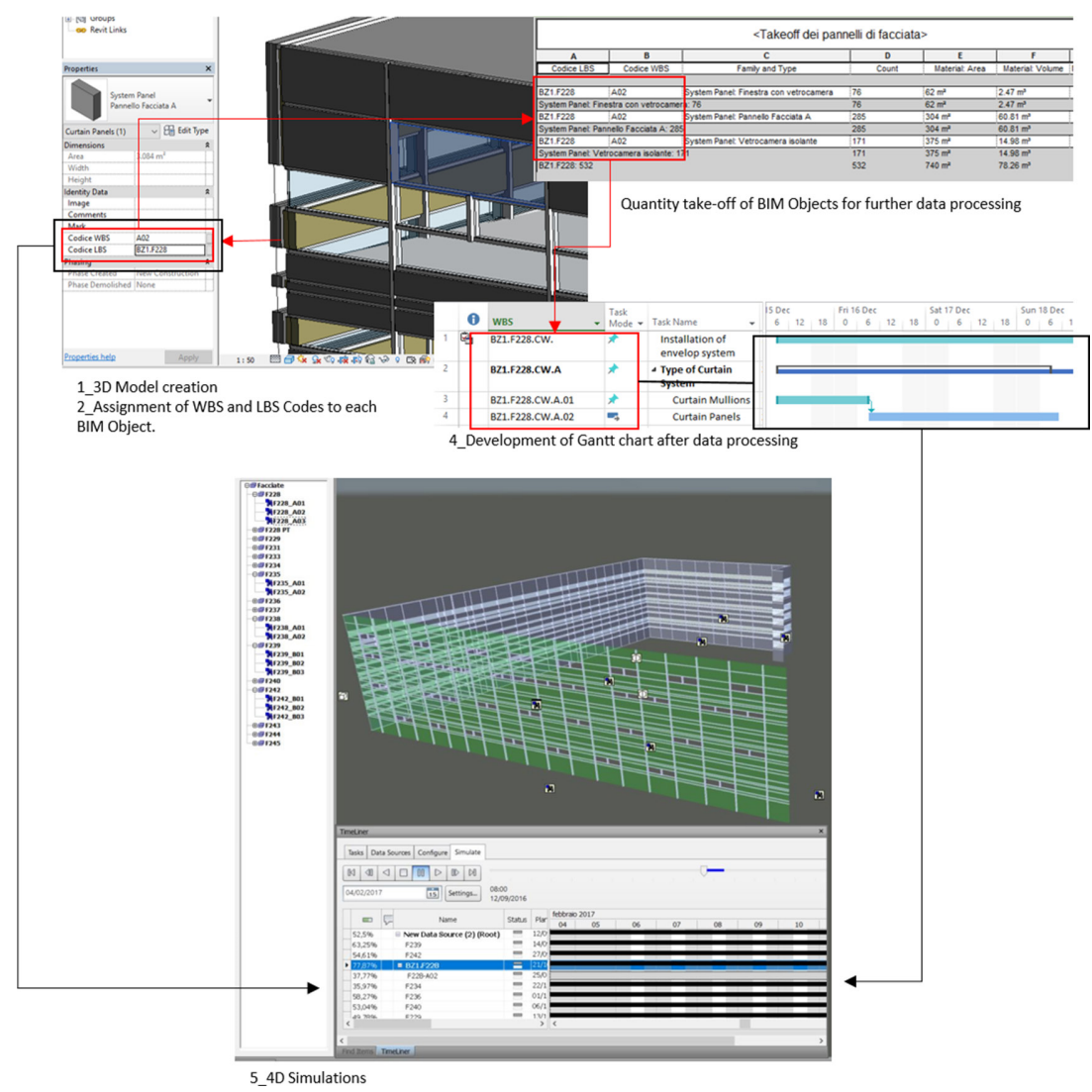

Figure 5: The process of the proposed BIM framework.

The main objective of this step was to compare the BIM scheduling process with the PRECISE process in order to analyse:

- The role of BIM in the digitalization of the construction scheduling;

- Benefits and criticism of BIM when applied to SMEs.

Within this step, objects' families have been modelled more in detail to reach the forth level (the Pitch level) of the proposed BIM framework. This required the adoption of an additional parametric tool, the Dynamo ${ }^{\circledR}$ plug-in for Revit ${ }^{\circledR}$, for the development of customized functionalities.

\section{DISCUSSION OF THE RESULTS}

5.1 The role of BIM in the digitalization of the PRECISE scheduling process

The case study demonstrates the central role of the quantity take-off functionality in the integration of BIM into the PRECISE scheduling process. Particularly, through the application of the location-based, quantity take-off provides additional information about objects' location 
and working task related. For this reason, quantity take-off makes construction scheduling more intuitive and precise. However, the process remains linear, fragmented and therefore with a relatively low degree of automation.

This is due to several factors. First, interoperability between software is mostly unidirectional. Models and scheduling files evolve separately along the process and when combined - only enduring the final stage of the process - they still fit as two separate entities into the same environment. When changes occur, the process re-starts from the beginning: re-modelling, re-extracting quantities, re-calculating task durations, re-visualizing the $4 \mathrm{D}$ model.

Second, only sophisticated software support a circular and integrated process. In fact, software houses are developing BIM tools integrating BIM with scheduling data. However, the entire set of current solutions available on the Italian market is not suitable for local SMEs. On the one hand, the high price of software integrating 4D functionalities, such as VICO® Software, prevents a broad diffusion among SMEs. The purchasing costs are relatively high if compared with common tools for BIM 4D, such as Navisworks ${ }^{\circledR}$ and Synchro®. Furthermore, free online trial versions are not available in the case of VICO® Software. On the other hand, some software houses provide plug-ins - such as Dynamo® for Autodesk Revit ${ }^{\circledR}$ - that enable the development of object-oriented scheduling functionalities. However, these require strong user skills in parametric design. Moreover, due to the rapid development of new BIM tools, the research team observed limits in the interoperability of software not developed in the same solar year. For example, Navisworks ${ }^{\circledR} 2016$ does not support any file formats from Revit 2017®. For a SME this is a real limit to the implementation of BIM, since they do not update their software annually.

In addition, the number of software solutions required during the BIM scheduling process is another critical factor. In fact, it requires four software solutions to reach the main objective. Each software solution (Autodesk Revit ${ }$, MS-Excel ${ }^{\circledR}$, MS-Project ${ }^{\circledR}$, and Autodesk Navisworks $\left.{ }^{\circledR}\right)$ has a specific objective: modelling, calculating, visualizing durations, combining the visualization of durations with the BIM model. The process implies a high level of commitment and risks to become highly time consuming.

Finally, the authors observed that lack of standardized procedures might be the reason for the fragmentation of the entire process. This organizational problem probably finds fundaments in the traditional approach used during the development of construction scheduling. Each construction company develops its own procedure, based on experiences and past knowledge. Therefore, it is also hard for a software house to develop a standardized process.

\subsection{Benefits and criticism of BIM for SMEs}

Adopting BIM for construction scheduling reveals both benefits and criticisms for SMEs. One of the benefits is the capacity to address the real need of visualization. In fact, the proposed BIM framework aimed at making the PRECISE methodology more intuitive through visualization. The aim has been partially reached. On the one hand, it can be stated that 4D simulations are easy to develop even for small and medium size construction projects. On the other hand, 4D simulations represent a result without manageable information. Simulations result from the combination of geometrical information, developed in a BIM authoring software, with a duration information, developed in scheduling software. This reveals a lack of informative contents. In fact, the case study shows that BIM for construction scheduling requires the development of a BIM Pitches model in order to be considered as useful for scheduling control during the operations on site. The BIM Pitches model is an informative 
model that contains information about productivity rate and productivity control. However, it is manually developed and a SME does not have time to develop an additional model. The development of the BIM Pitches model should be automated through a software capable to interpret the information of the scheduling process. Nowadays, existing software solutions do not have such a functionality, as they only focus on visualizing the 4D process without managing the related information.

An additional benefit of BIM is that information modelling provides accurate quantity estimations, particularly useful in determining framings and standardized components as well as in reducing the number of spreadsheets required. As showed in the case study, the use of BIM is more accurate in determining quantities and generating shop drawings than traditional CAD tools and spreadsheets. Benefits of information modelling have an impact also on: the reduction of unusualness material that occupy precious space in the warehouse, the reduction of human errors that cause re-works, the reduction of paper consumption and the loss of data along the scheduling process.

Conversely, information modelling reveals also some criticisms. Modelling for scheduling may become extremely time-consuming since a relatively high level of detail is required. During the full implementation, modellers developed three customized families of panels. Each typology of panel is made of different type of the following objects: a) one layer of insulation material, b) two horizontal metallic beams, c) two vertical metallic mullions, d) two horizontal panels of aluminium e) one vertical panel of aluminium. A specific task corresponds to each of the aforementioned objects. Modellers made use of their advanced knowledge of the software Revit and of the plug-in Dynamo, to develop such customized parametric families. It took 10 days to implement these families into the model since several problems occurred. The poor interface of Revit, for instance, caused errors and re-works. The rotated shape of the façade (two degrees), limited the fitting of the customized panels, as objects previously modelled with errors.

\section{CONCLUSION AND FUTURE IMPLEMENTATIONS}

This paper proposes a BIM framework for construction scheduling to be applied in the context of SMEs. A case study has been used to verify its applicability, particularly examining the role of BIM in digitalizing the construction scheduling process and the benefits and criticisms of its application to SMEs.

On the base of the emerging evidence, the authors derived and discussed benefits and drawbacks of BIM applications for SMEs.

BIM has a fundamental role in digitalizing the construction scheduling process. The case study shows the potentialities of BIM in the digitalization of the PRECISE scheduling process even if such potentialities remains partly unexploited. In particular, the Quantity Take-off functionality reveals its main role in linking the BIM model with the scheduling process. Therefore, the authors believe that further research activities should focus on how this functionality can support the transition from a linear to a circular process. A first concept of such a transition process has been proposed within this paper, introducing potentials of the BIM Pitch. However, such a concept requires further fine-tuning through more targeted research activities.

Furthermore, the case study confirms that BIM has two major benefits, namely the provision of accurate quantity take off and automated shop drawings and visualization. These features ensure efficient time management and ultimately prevent the occurrence of human errors. However, there are certain limits to be taken into account. Critical factors of BIM are the following: 
1. Excessive effort and commitment to develop detailed models mostly applicable for visualization purposes only;

2. Unsuitability of the BIM Pitch concept for SMEs since it is highly time consuming to develop as additional model;

3. Prohibitive cost of the technologies and lack of BIM competences available in the job market.

Fraunhofer Italia is already working in further implementation of the proposed BIM framework as partner of the H2020 ACCEPT project (https://accept-project.com/). ACCEPT involves eleven partners from seven different countries and it focuses on the implementation of an ICT platform that integrates tools such as BIM and Augmented Reality for the management of the construction site. This project is implementing the proposed BIM framework in the ACCEPT platform, which will be tested in several international construction projects. In this context, the research team is working on:

1. Further development of the BIM Pitch concept;

2. Developing a BIM 4D plug-in to match BIM metadata data and MS-Project ${ }^{\circledR}$ scheduling and import to the ACCEPT platform in order to enable the more reliable construction scheduling and controlling;

3. Defining guidelines for professionals for modelling BIM 4D and managing the process behind.

\section{ACKNOWLEDGEMENTS}

The authors gratefully acknowledge: Alexander Alber and Martin Vallazza of BLS Company, who provided PDF drawings and general information regarding the NOI Technology Park project and 'The Black Monolith' building; Robert Ploner, project manager of Metal Ritten Company, who provided detailed shop drawings and detailed information for the installation of the façade of 'The Black Monolith', which was used in this research.

\section{REFERENCES}

[1] Miller, R., Strombom, D., Iammarino, M. \& Black, B., The commercial real estate revolution: Nine transforming keys to lowering costs, cutting waste and driving change in a broken industry, Wiley, 2009.

[2] Krause, D., Matt, D., Bullinger, S. \& Rauch, R., Schlanke Prozesse in Baunetzwerken, Survey build4future, Fraunhofer Verlag, 2012.

[3] Malacarne, G., Pasetti Monizza, G., Ratajczak, J., Krause, D., Benedetti, C. \& Matt, D., Prefabricated timber facade for the energy refurbishment of the Italian building stock: the Ri.Fa.Re. project. Energy Procedia, 96, pp. 788-799, 2016. https://doi.org/ 10.1016/j.egypro.2016.09.141

[4] Dallasega, P., Rauch, E. \& Matt, D., Increasing productivity in ETO construction projects through a lean methodology for demand predictability. International Conference on Industrial Engineering and Operation Management (IEOM), 2015. https://doi.org/10.1109/IEOM.2015.7093734

[5] Dallasega, P., Matt, D. \& Krause, D., Design of the building execution process in SME construction networks. Proceedings of the 2nd International Workshop on Design in Civil and Environmental Engineering, pp. 7-15, 2013. 
[6] Forbes, L.H. \& Ahmed, S.M., Modern construction. Lean project delivery and integrated practices, CRC Press: Boca Raton, pp. 94-100, 2011.

[7] Rother, M. \& Shook, J., Learning to see - Value Stream Mapping to Create Value and Eliminate Muda, Lean Enterprise Institute, Cambridge, 2009.

[8] Dallasega, P., Marengo, E., Nutt, W., Rescic, L., Matt, D. \& Rauch, E., Design of a Framework for supporting the Execution-Management of Small and Medium sized Projects in the AEC-industry. Proceedings of the 4th International Workshop on Design in Civil and Environmental Engineering, pp. 60-71, 2015.

[9] Malsane, S.M. \& Sheth, A.Z., Simulate construction schedules using BIM 4D application to track progress, International Journal of Mechanical and Product Engineering, 3, pp. 54-58, 2015.

[10] Hardin, B. \& Mccool, D., BIM and construction management, Wiley: Indianapolis, pp. 20-21, 2015.

[11] Ratajczak, J., Malacarne, G., Krause, D. \& Matt, D., The BIM approach and stakeholders integration in the AEC Sector - Benefits and obstacles in South Tyrolean context. Proceedings of the 4th International Workshop on Design in Civil and Environmental Engineering, pp. 32-40, 2015.

[12] Art. 23 D.gls. n.50, 18 Aprile 2016, http://www.bosettiegatti.eu/info/norme/ statali/2016_0050.htm, Accessed April 04, 2017.

[13] Ciribini, A.L.C., BIM e Digitalizzazione dell'Ambiente Costruito, Grafill: Palermo, pp. 387-395, 2016.

[14] Gobbi, G. \& Thurner, B., Alto Adige in cifre 2016, Provincia Autonoma di Bolzano Alto Adige Istituto Provinciale di Statistica, Bolzano, 2016.

[15] Metkari, A.A. \&Attar, A. C., Application of building information modeling tool for building project. International Journal of Science and Research (IJSR), 4, pp. 324-329, 2015.

[16] Sattineni, A. \& Bradford II, R.H., Estimating with BIM: a survey of US construction companies. Proceedings of the 28th International Symposium on Automation and Robotics in Construction, pp. 564-569, 2011.

[17] Liu, H., Lu, M. \& Al-Hussein, M., BIM-based integrated framework for detailed cost estimation and schedule planning of construction projects. Proceedings of the 31st International Symposium on Automation and Robotics in Construction and Mining, pp. 286-294, 2014.

[18] Boton, C., Kubicki, S. \& Halin, G., 4D/BIM simulation for pre-construction and construction scheduling. Multiple levels of development within a single case study. Proceedings of the Creative Construction Conference, pp. 500-505, 2015. 